\title{
Forskolin alleviates diabetic nephropathy via inhibition of aldose reductase and advanced glycation end products formation
}

\author{
Damera S, Ajmera RR and Ciddi $V^{*}$ \\ University College of Pharmaceutical Sciences, Kakatiya University, Warangal, Telangana, India
}

\begin{abstract}
Objectives: Various mechanisms including polyol pathway along with a complex integrating paradigm with Aldose reductase (AR) and advanced glycation end products (AGE) formation have been implicated in the pathogenesis of diabetic nephropathy.

Methods: The present study was aimed at investigating a well-known antioxidant, Forskolin for its therapeutic role in streptozotocin-induced diabetic nephropathy in rats. The effect of Forskolin was investigated by assessing the key markers of kidney function along with the morphological changes in the kidney. Further, the effect of Forskolin on the formation of AGEs and AR inhibition and lipid peroxidation was compared with that of a standard AR inhibitor, fidarestat.

Results: The results revealed that Coleus forskohlii methanolic extract and Forskolin significantly $(\mathrm{P}<0.05)$ decreased the blood glucose levels, urinary protein excretion, serum creatinine and blood urea nitrogen in diabetic rats. Administration of Forskolin to diabetic rats decreased kidney lipid peroxides and nitrate levels along with decrease in AGEs formation. In addition, Forskolin was found to inhibit kidney AR activity.

Conclusion: Thus, the results obtained in this study underline the potential of Forskolin as a possible therapeutic agent against diabetic complications such as nephropathy.
\end{abstract}

\section{Introduction}

Diabetes mellitus has assumed epidemic proportions worldwide and such as large burden of diabetes is sure to bring an immense burden of complications with it. Among the various complications, nephropathy is one of the most important, both in terms of short term and long term morbidity to the individual [1]. In spite of treating diabetic nephropathy patients with agents such as angiotensin converting enzyme (ACE) inhibitors, angiotensin antagonists and antihypertensive agents, enormous number of diabetic patients still continue to suffer from diabetic kidney disease [2]. Diabetic nephropathy is usually attributed to biochemical alterations in glucose metabolism such as increase in polyol flux along with elevated blood and tissue levels of glycosylated proteins leading to haemodynamic changes within the kidney tissue [3].

Even though, at present, several approaches such as strict control of blood glucose level and ACE inhibitors use for the management of diabetic nephropathy they could not satisfy the clinical need for the treatment of disease which led to the research on alternative pathways such as inhibition of polyol pathway and formation of advanced glycation end products (AGEs). This led to the development of newer class of drugs which inhibit the aldose reductase (AR) an enzyme in the polyol pathway [4-5]. Further, the failure of various synthetic AR inhibitors (ARIs) due to their toxic effects and absence of satisfactory efficacy, there is a pressing need for the search of new ARIs from natural sources [6]. Thus, the present study was designed to assess various biochemical and physiological alterations with special emphasis on the role of polyol pathway and AGEs in the therapy of diabetic nephropathy.
Coleus forskohlii Briq. (Lamiaceae) is an aromatic Indian herb. Ayurvedic practitioners have used Coleus to treat asthma, chronic cough, strangury, calculus, gonorrhea, piles, fever epilepsy, heart diseases, abdominal colic, dyspepsia, respiratory problems, nervous system disorders as insomnia and convulsions [7].

Forskolin is the main constituent in the roots of C. forskohlii; it is a heterocyclic labdane diterpene with diverse pharmaceutical applications such as anti- HIV, antitumor, in the treatment of antiglaucoma, hypertension, and heart failure [8].

\section{Materials and methods}

\section{Chemicals}

Steptozotocin (STZ) was purchased from Sigma Aldrich (Bangalore, India) and Coleus forskohlii methanolic extract (CME) and Forskolin (FSL) were procured from Yucca enterprises,Mumbai, India. Reduced Nicotinamide adenine dinucleotide phosphate (NADPH) and bovine serum albumin (BSA) were obtained from HiMedia Laboratories (Mumbai, India). Fidarestat was supplied by Symed Labs Ltd (Hyderabad, India). All the other chemicals were of analytical grade.

${ }^{\star}$ Correspondence to: Ciddi Veeresham, Professor of Pharmacy, University College of Pharmaceutical Sciences, Kakatiya University, Warangal, Telangana, India - 506009, E-mail: ciddiveereham@yahoo.co.in

Key words: coleus forskohlii, forskolin, aldose reductase, advanced glycation end products, diabetic nephropathy

Received: April 19, 2019; Accepted: May 20, 2019; Published: June 01, 2019 


\section{Animals}

Male Wistar rats (180-200 g) were obtained from Jeeva life sciences Pvt. Ltd (Hyderabad, India), housed at $25^{\circ} \mathrm{C}$ and relative humidity of $45-55 \%$ under a natural light: dark cycle of $12 \mathrm{~h}$ day light and $12 \mathrm{~h}$ of darkness with unrestricted access to food and water. Throughout the experimental period, the rats were fed with balanced pellet diet. The experimental protocol was approved by the Institutional Animal Ethics Committee (IAEC no: IAEC/23/UcPSc/KU/2016) and executed in agreement with the guiding principles of Committee for Control and Supervision of Experimentation on Animals, Government of India on animal experimentation.

\section{Animal treatment}

Diabetes was induced by i.p. administration of STZ freshly prepared in $0.1 \mathrm{M}$ citrate buffer $(\mathrm{pH} 4.5)$ to the rats fasted overnight at a dose of $50 \mathrm{mg} / \mathrm{kg}$ of body weight. After one week of STZ administration, the animals were fasted for $12 \mathrm{~h}$ followed by withdrawal of blood by retroorbital plexus. Blood glucose levels were estimated by glucose oxidase method [9] and the animals with more than $250 \mathrm{mg} / \mathrm{dL}$ were treated as diabetic animals. After a period of 6 weeks, the diabetic animals were divided into 5 groups $(\mathrm{n}=8)$ : Group I receives $0.1 \mathrm{M}$ citrate buffer, Group II served as diabetic control whereas Group III and Group IV received CME $(100 \mathrm{mg} / \mathrm{kg})$, FSL $(10 \mathrm{mg} / \mathrm{kg})$ respectively, and Group $\mathrm{V}$ treated with fidarestat $(1 \mathrm{mg} / \mathrm{kg})$ for a period of 3 weeks. Blood was withdrawn from the retro orbital plexus followed by collection of $24 \mathrm{~h}$ urine samples on the last day by means of metabolic cages after which the animals were sacrificed by cervical dislocation. Kidneys were then perfused with normal saline, isolated, weighed and biochemical estimations were done.

\section{Biochemical estimations}

Plasma glucose [10], plasma and urine creatinine [11], blood urea nitrogen (BUN) [12], and total urine protein [13] were estimated using commercially available diagnostic kits (Proton Biologicals Ltd., India). Glomerular filtration rate (GFR) was calculated using $24 \mathrm{~h}$ urine volume and creatinine content in urine and plasma by the reported formula [14].

\section{Estimation of AGEs in kidneys}

AGEs levels in the kidneys were determined by the method described by Sensi et al., (1996) [15]. Briefly, perfused kidneys were homogenized in $2 \mathrm{~mL}$ of $0.25 \mathrm{M}$ sucrose followed by centrifugation at $900 \mathrm{x} \mathrm{g}$ at $4^{\circ} \mathrm{C}$ and the supernatant was separated. The pellet was resuspended in $2 \mathrm{~mL}$ sucrose solution and centrifuged. The supernatant was separated and mixed with the previous one. The proteins present were precipitated by adding equal volume of trichloroacetic acid (TCA). Following centrifugation at $4^{\circ} \mathrm{C}, 900 \mathrm{x}$ g, the protein pellet obtained was mixed with $1 \mathrm{~mL}$ methanol twice to remove the lipid fraction. The insoluble protein, after washing with $10 \%$ cooled TCA was centrifuged and the residue was solubilised in $1 \mathrm{~mL}$ of $1 \mathrm{~N} \mathrm{NaOH}$ and the protein content was estimated by determining the absorbance at $280 \mathrm{~nm}$ against BSA standard curve. The AGEs content was then measured flourimetrically with an emission at $440 \mathrm{~nm}$ and excitation at $370 \mathrm{~nm}$, and the results were expressed as relative fluorescence units $(\mathrm{RFU}) / \mathrm{mg}$ protein.

\section{Histological study}

A portion of the kidney tissue was fixed in $10 \%$ formalin for a week at room temperature. The specimens were then dehydrated with graded ethanol series, cleared in xylene and embedded in paraffin wax. The blocks were then sectioned into $5 \mu \mathrm{m}$ thick using rotary microtome. The obtained sections were stained with hematoxylineosin and the photomicrographs were obtained under light microscope at a magnification of $400 \mathrm{x}$ and analyzed by double blind analysis and scored by the previous method [16]. Tubular injury was scored by grading the percentage of affected tubules under ten randomly selected, non-overlapping fields as follows: $0,0 \% ; 1, \leq 10 \% ; 2,11-25 \% ; 3,26$ $45 \%$; 4, 46-75\%; and 5, 76-100\%. To score injured tubules, whole tubule numbers per field were considered as standard. The grading percentage was calculated in each field as follows: injury score $(\%)=$ (number of injured tubules/number of whole tubules) x100.

\section{Kidney AR activity}

AR activity was measured by spectrophotometrically by the method of Kim and Oh (1999) [17]. Briefly, the reaction mixture consisted of $300 \mu \mathrm{L}$ of $0.15 \mathrm{mM}$ NADPH, crude enzyme preparation, and the final volume was made up to $2.7 \mathrm{~mL}$ with sodium phosphate buffer. The reaction was initiated by addition of $300 \mu \mathrm{L}$ of $10 \mathrm{mM}$ DL-glyceraldehyde as substrate and absorbance was measured at $340 \mathrm{~nm}$ using double beam UV spectrophotometer (SL210, Elico, India) for $1 \mathrm{~min}$ at $10 \mathrm{sec}$ interval. Absorbance was recorded for all the concentrations in triplicate.

\section{Oxidative stress parameters}

Oxidative stress parameters (Reduced glutathione levels and MDA levels) were estimated according to the method previously described by Hiroshi Okhawa et al. [18].

\section{Estimation of reduced glutathione (GSH) levels in kidney}

To the $0.2 \mathrm{~mL}$ of $10 \% \mathrm{w} / \mathrm{v}$ tissue homogenate, $0.2 \mathrm{~mL}$ of $5 \%$ trichloroacetic acid was added and allowed to stand for $5 \mathrm{~min}$. followed by centrifugation. To $0.2 \mathrm{~mL}$ of the supernatant $2.3 \mathrm{~mL}$ of phosphate buffer (pH7.6), 0.5mL of DTNB was added, then incubate for $5 \mathrm{~min}$ and measure the absorbance at $412 \mathrm{~nm}$ within $15 \mathrm{~min}$.

\section{Estimation of MDA in kidney}

The whole tissue sample homogenate $(10 \%)$ was prepared in icecold $0.1 \mathrm{M}$ phosphate buffer $\mathrm{pH}$ 7.4. The reaction mixture contains $0.2 \mathrm{~mL}$ tissue homogenate $(10 \%), 1.5 \mathrm{ml}$ acetic acid $(20 \%), 1.5 \mathrm{~mL}$ thiobarbituric acid $(0.8 \%)$ and $0.2 \mathrm{~mL}$ SLS $(8.1 \%)$.The mixture was made upto $4 \mathrm{~mL}$ with distilled water and heats it at $95^{\circ} \mathrm{C}$ for $60 \mathrm{~min}$. on oil bath. After cooling under tap water, add $1 \mathrm{~mL}$ of distilled water and $5 \mathrm{~mL}$ of mixture of $\mathrm{n}$ - butanol: pyridine (15:1) was added and shaken vigorously. Then the mixture was centrifuged at $4000 \mathrm{rpm}$ for $10 \mathrm{~min}$ and separate organic layer and measure absorbance at $532 \mathrm{~nm}$.

\section{Serum nitrate levels}

Serum nitrate levels were estimated according to the method described by Miranda et al. (2001) [19]. The reaction between nitrite, sulphonamide and $\mathrm{N}$-(1-napthyl) ethylenediamine leading to the formation of an azo product was quantified by measuring the absorbance of the product at $543 \mathrm{~nm}$. The concentrations were determined using a standard curve of sodium nitrate and the results were expressed as $\mu \mathrm{mol} / \mathrm{L}$ in serum samples.

\section{Statistical analysis}

The data were analysed by using analysis of variance (ANOVA) followed by Bonferroni post-test. All the values were expressed as mean \pm SEM and the criterion for statistical significance was considered to be $\mathrm{P}<0.05$. 


\section{Results}

\section{Effect on blood glucose}

Induction of diabetes led to a significant $(\mathrm{P}<0.05)$ increase in blood glucose levels in the control group when compared to the naïve animals. However, administration of CME $(100 \mathrm{mg} / \mathrm{kg})$, FSL $(10 \mathrm{mg} /$ $\mathrm{kg})$ for 3 weeks led to a significant $(\mathrm{P}<0.05)$ decrease in the blood glucose when compared to the control group, whereas, administration of fidarestat $(1 \mathrm{mg} / \mathrm{kg})$ did not show any significant decrease in blood glucose when compared to control animals (Table 1).

\section{Renal function related parameters}

Blood urea nitrogen, Urinary protein and plasma creatinine were significantly increased in the diabetic control group when compared to naïve animals. However, administration of CME $(100 \mathrm{mg} / \mathrm{kg})$, FSL $(10 \mathrm{mg} / \mathrm{kg})$ or fidarestat $(1 \mathrm{mg} / \mathrm{kg})$ for 3 weeks led to a significant decrease in the urinary albumin, plasma creatinine and BUN when compared to the control group (Table 1). Similarly, GFR was found to be significantly $(\mathrm{P}<0.05)$ decreased in control group when compared to the naive animals. Administration of CME and FSL or fidarestat for 3 weeks led to a significant $(\mathrm{P}<0.05)$ increase in the GFR when compared to the control group.

\section{Effect of CME and FSL on kidney AGEs and AR (in vitro)}

Induction of diabetic nephropathy in rats led to a significant increase in kidney AGEs levels when compared to naïve animals. Administration of CME $(100 \mathrm{mg} / \mathrm{kg})$, FSL $(10 \mathrm{mg} / \mathrm{kg})$ significantly $(\mathrm{P}<$ $0.05)$ reduced the AGEs levels in kidneys when compared to control group. However, administration of fidarestat $(1 \mathrm{mg} / \mathrm{kg})$ produced an insignificant decrease in AGEs levels when compared to control group (Figure 1). Similarly, the activity of kidney AR was significantly increased in diabetic rats compared to the normal rats. Table 2 showed in vitro kidney AR activity. In this CME, FSL and FDST of different concentrations showed dose dependent percentage inhibition with low IC50 values when compared to the standard fidarestat.

\section{Histology}

Light microscopic study of tissue sections revealed that normal rats consisted of intact glomeruli with normal mesangial matrix. However, diabetic rats exhibited glomeruli with mesangial expansion which is reflected by the changes in histopathological scoring and loss of some podocyte cells in diabetic rats. However, administration of CME $(100 \mathrm{mg} / \mathrm{kg})$, FSL $(10 \mathrm{mg} / \mathrm{kg})$ or fidarestat $(1 \mathrm{mg} / \mathrm{kg})$ led to the reduction in mesangial expansion and prevention of loss of podocyte cells (Figure 2).

Table 1. Biochemical parameters in STZ induced diabetic nephropathy in rats. Data was analyzed by one Way ANOVA followed by Dunnet's test

\begin{tabular}{|c|c|c|c|c|}
\hline Parameter & Naive & Control & Diabetic +FDST & Diabetic+ CME \\
\hline Blood glucose (mg/dL) & $108.83 \pm 8.72$ & $380 \pm 25.81 \#$ & $265 \pm 6.09$ & $103.66 \pm 4.08^{*}$ \\
\hline BUN (mg/dL) & $7.97 \pm 0.36$ & $50.12 \pm 2072 \#$ & $104.83 \pm 6.11^{*}$ \\
\hline Urine protein (mg/24h) & $30.20 \pm 3.72$ & $34.22 \pm 2.66 \#$ & $40.63 \pm 7.94 *$ & $21.36 \pm 8.89^{*}$ \\
\hline GFR (ml/min) & $2.14 \pm 0.11$ & $0.97 \pm 0.076 \#$ & $24.73 \pm 1.80^{*}$ & $23.79 \pm 0.92 *$ \\
\hline Plasma creatinine (mg/dL) & $1.12 \pm 0.20$ & $3.10 \pm 0.83 \#$ & $1.91 \pm 0.05 *$ & $1.63 \pm 0.04^{*}$ \\
\hline Urinary creatinine (mg/dL) & $1.24 \pm 0.42$ & $3.31 \pm 0.87 \#$ & $2.38 \pm 0.79 *$ & $0.913 \pm 0.54^{*}$ \\
\hline
\end{tabular}

Values are expressed as mean $\pm \mathrm{SEM}$. $(\mathrm{n}=8) \# P<0.05$ as compared to naive group, $* P<0.05$ as compared to control group

Table 2. Effect of CME and FSL on rat kidney aldose reductase inhibitory activity in vitro

\begin{tabular}{|c|c|c|c|c|}
\hline & Concentration $(\mu \mathrm{g} / \mathrm{ml})$ & \% Inhibition & $\mathrm{IC}_{50}(\mu \mathrm{g} / \mathrm{ml})$ & $\mathrm{IC}_{50}(\mu \mathrm{M})$ \\
\hline \multirow[t]{3}{*}{ CME } & 10 & $63.458 \pm 5.534$ & $1.053 \pm 1.25$ & \\
\hline & 50 & $76.139 \pm 0.0063$ & & \\
\hline & 100 & $86.088 \pm 0.0120$ & & \\
\hline \multirow[t]{3}{*}{ FSL } & 1 & $73.591 \pm 0.028$ & $1.681 \pm 2.14$ & 4.108 \\
\hline & 5 & $85.603 \pm 0.0049$ & & \\
\hline & 10 & $89.660 \pm 7.546$ & & \\
\hline \multirow[t]{3}{*}{ FDST } & 0.1 & $3.09 \pm 0.951$ & $5.714 \pm 2.56$ & 20.46 \\
\hline & 0.5 & $61.52 \pm 2.013$ & & \\
\hline & 1 & $73.459 \pm 2.087$ & & \\
\hline
\end{tabular}

All values are expressed as mean \pm S.D, $n=3 . \mathrm{IC}_{50}, 50 \%$ Inhibitory concentration; $\mathrm{SD}$, Standard deviation

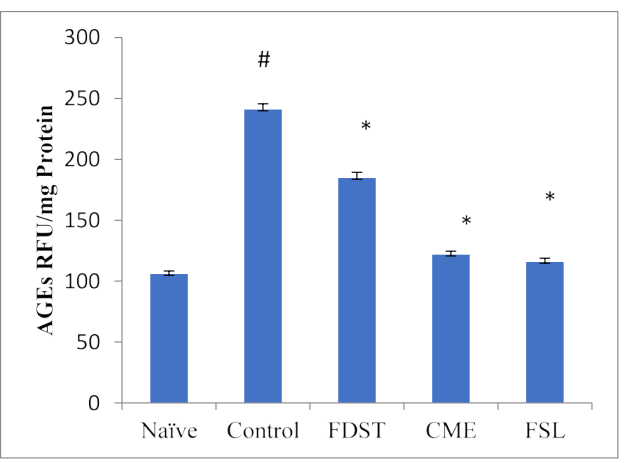

Figure 1. Effect of CME and FSL on alterations in AGE levels in STZ induced diabetic nephropathy in rats. RFU: Relative Fluorescence Units. Data was analysed by one-way ANOVA followed by Bonferroni post-test

$(\mathrm{n}=8)$ \# $\mathrm{P}<0.05$ as compared to naïve group, $* P<0.05$, as compared to control group 


\section{Effect of CME and FSL onMDA, reduced glutathione and nitrate levels (kidney)}

A Thiobarbituric acid reactive substance (TBARS) (MDA) was significantly $(\mathrm{P}<0.05)$ elevated in whole kidney tissues of diabetic untreated rats when compared to naïve animals. Treatment with CME, FSL or fidarestat significantly reverted the TBARS (MDA) content in renal tissues. Reduced glutathione (GSH) levels in kidney tissues were significantly increased in CME and FSL treated groups when compared to that of diabetic control group (Table 3). Similarly, total nitrite/nitrate levels in serum were significantly $(\mathrm{P}<0.05)$ elevated in the diabetic untreated group when compared to naïve animals. However, treatment with CME, FSL and fidarestat at a dose of $100 \mathrm{mg} / \mathrm{kg}, 10 \mathrm{mg} / \mathrm{kg}$ and $1 \mathrm{mg} / \mathrm{kg}$ respectively, lowers the diabetes induced increase in nitrate levels compared to the untreated diabetic rats (Figure 3).

\section{Discussion}

A large number of studies have documented the evidence that progression of diabetes leads to various complications among which

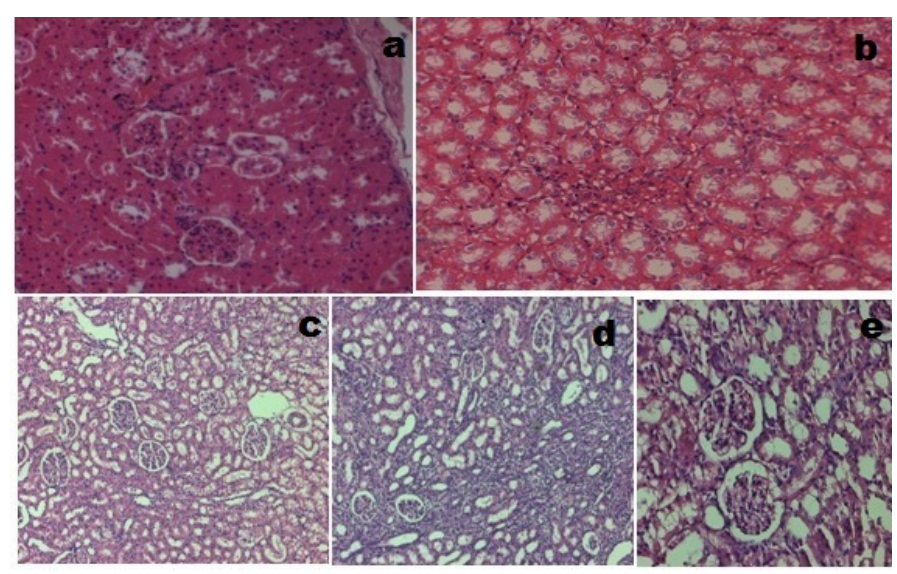

Figure 2. Glomerular morphology changes in different experimental groups (HE stain $400 \times$ magnification). (a) Naive group. (b) Control group. (c) Diabetic + Fidarestat (d) Diabetic + CME (e) Diabetic + FSL. Data was analysed by one way ANOVA followed by Bonferroni post-test. (n=8) ${ }^{\#} P<0.05$ as compared to naïve group, ${ }^{*} P<0.05$, as compared to control group

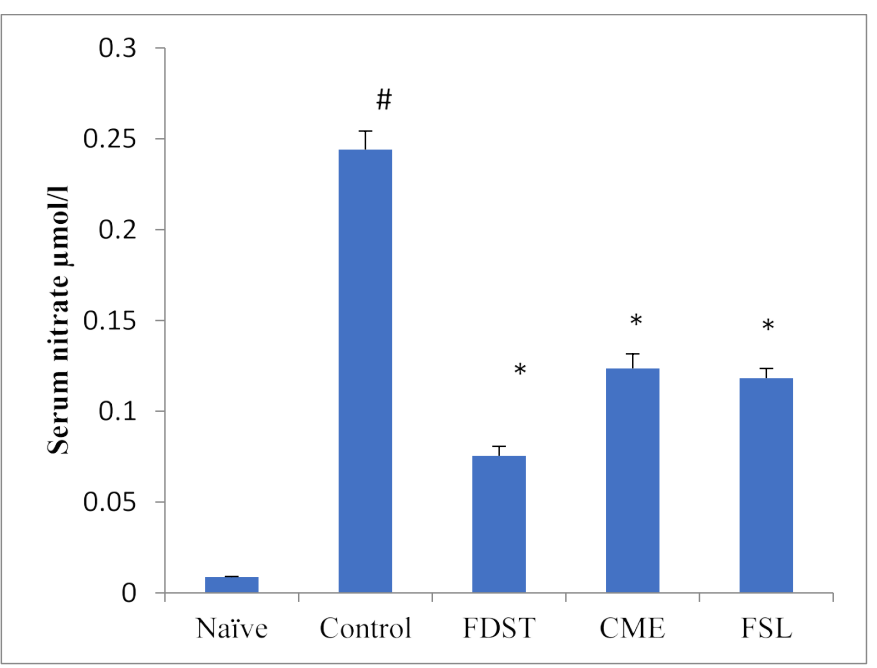

Figure 3. Effect of CME and FSL on alterations in Serum nitrate levels in STZ induced diabetic nephropathy in rats. Data was analysed by one way ANOVA followed by Bonferroni post-test. $(\mathrm{n}=8){ }^{\#} P<0.05$ as compared to naïve group, ${ }^{*} P<0.05$, as compared to control group
Table 3. Effect of CME and FSL on oxidative stress levels in STZ induced diabetic nephropathy in rats. Data was analyzed by one-way ANOVA followed by Bonferroni posttest

\begin{tabular}{|c|c|c|c|c|c|}
\hline & Naïve & Control & FDST & CME & FSL \\
\hline $\begin{array}{c}\text { MDA- } \\
\text { kidney } \\
\text { (nmol/ml) }\end{array}$ & $1.57 \pm 0.11$ & $11.986 \pm 0.74 \#$ & $1.623 \pm 0.060 *$ & $0.866 \pm 0.070 *$ & $0.558 \pm 0.082 *$ \\
\hline $\begin{array}{c}\text { GSH- } \\
\text { kidney } \\
\text { (nmol/ml) }\end{array}$ & $45.87 \pm 3.40$ & $16.45 \pm 1.31 \#$ & $18.783 \pm 5.85 *$ & $30.753 \pm 3.85 *$ & $32.753 \pm 2.96 *$ \\
\hline
\end{tabular}

(n=8) \# $P<0.05$ as compared to naïve group, ${ }^{*} P<0.05$, as compared to control group

nephropathy is a serious complication with an increasing prevalence worldwide [20]. The disease is characterized by morphological and ultra-structural changes in the kidney including expansion of the molecular matrix. Even though, the pathogenesis of diabetic nephropathy is complex and still not fully elucidated, few biochemical alterations such as increase in polyol pathway flux, increased AGEs formation, have been actively studied for their role in the development of diabetic nephropathy.

Diabetic nephropathy which is characterized by increased matrix proteins leading to decreased GFR is considered as a marker for the progression of the disease. Elevation of serum creatinine and BUN in diabetic rats is used as an index of altered GFR in diabetic nephropathy [21]. Results of the present study have corroborated with the previous reports [22] in which administration of STZ led to the induction of diabetic nephropathy with a significant decrease in GFR which is evident from the elevated levels of serum creatinine and BUN. However, administration of CME and FSL for 3 weeks normalized various kidney function parameters such as, creatinine and BUN levels leading to improved GFR in diabetic rats. Treatment with fidarestat led even though did not restore the glucose levels in diabetic rats, it led to a significant decrease in the UFR to normal levels (evident from the increased GFR) which can be attributed to its potent ARI and antioxidant activity. Development of protienurea which is regarded as a vital marker in diabetic nephropathy is mainly due to the increased excretion of proteins caused by the decrease in GFR. The mechanism of increased excretion of these proteins has also been attributed to the decreased tubular reabsorption during diabetes [23]. In consistent with the above findings, the present study exhibited higher urine protein levels in diabetic rats when compared to naive group. On the other hand administration of CME and FSL significantly reduced the degree of protienurea.

Hyperglycemia accelerates the activity of AR which is a key enzyme in the conversion of glucose to sorbitol with a parallel decrease in $\mathrm{NADPH}$ and glutathione. This loss of antioxidant reducing equivalents results in the increased susceptibility to oxidative stress associated with intracellular reactive oxygen species [24]. Further, accumulation of impermeable sorbitol results in the increased glycation of intracellular proteins leading to the elevated formation of AGEs. Increased AR activity triggers various signal transduction pathways such as PKC and JNK resulting in the overproduction of cytokines such as TGF- $\beta$. Increasing evidence from several studies reported the elevation of AR in the renal tissue during diabetes and a favourable influence of ARIs in diabetic nephropathy [25]. Thus, the preliminary studies which suggested CME and FSL as a potent ARI in vitro were evaluated for its therapeutic efficacy in diabetic nephropathy.

In the present study, AR activity was significantly increased in diabetic rats, which was inhibited by administration of CME and FSL. Consequently, the in vivo ARI potential of CME and FSL was also established. Further, chronic hyperglycemia leads to accumulation of 
AGEs in the kidney with consequent loss of membrane integrity [26] and since AGEs play an important role in the progress of diabetic nephropathy, the levels of AGEs formation in the kidneys were estimated. Administration of CME and FSL to diabetic rats significantly inhibited the formation of AGEs demonstrating its beneficial role in the therapy of the disease. The results support the earlier report by $\mathrm{Lv}$ et al. (2010) [27] where presence of CME and FSL effectively prevented the trapping of methylglyoxal, a reactive diacarbonyl intermediate in the formation of AGEs. Further, administration of fidarestat led to an insignificant decrease in the AGEs which can be attributed to the high glucose levels, never the less, the potent AR inhibitory activity of the drug along with its ability to inhibit the oxidative stress in the rats could have contributed to the normalization of the kidney function in the diabetic rats.

Several studies involving both preclinical and clinical studies suggest that oxidative stress play a vital role in the development of diabetic complications. Hyperglycemia induces free radical generation, combined with AR mediated decrease in NADPH and glutathione leads to oxidative stress [28].

TBARS (MDA) which is a marker of lipid peroxidation in kidneys, was increased in the diabetic untreated rats and this increase in TBARS was significantly decreased by administration of CME and FSL. Moreover, nitrate was also considered as an index of oxidative damage [29] since these are oxidation products of NO. In the present investigation, observed that the serum and nitrate levels in CME, FSL or fidarestat treated animals were significantly decreased demonstrating its protective role against STZ-induced diabetic nephropathy. This effect can be attributed to its antioxidant activity along with its ability to inhibit polyol pathway induced oxidative stress.

\section{Conclusion}

In conclusion, the therapeutic potential of CME and FSL against STZ induced diabetic nephropathy can be attributed to its combined effect of its ability to inhibit AR and AGEs formation along with its well-known antioxidant and antihyperglycemic effects. However further studies in diabetic model with knockout AR rats are necessary to confirm the exact mechanism of action along with its effect on various other diabetic complications

\section{Acknowledgements}

Symed Labs Ltd (Hyderabad, India) are gratefully acknowledged for the generous gift of fidarestat sample.

\section{Conflicts of interest}

There is no conflict of interest between any of the authors.

\section{References}

1. Rossing P (2006) Diabetic nephropathy: Worldwide epidemic and effects of current treatment on natural history. Curr Diab Rep 6: 479-683. [Crossref]

2. Dronavalli S, Duka I, Bakris GL (2008) The pathogenesis of diabetic nephropathy. Nat Clin Pract Endocrinol Metab 4: 444-452. [Crossref]

3. Aurell M, Bjorck S (1992) Determinants of progressive renal disease in diabetes mellitus. Kidney Int Suppl 36: S38-42. [Crossref]

4. Jennings PE, Nightingale S, Le Guen C, Lawson N, Williamson JR, et al. (1990) Prolonged aldose reductase inhibition in chronic peripheral diabetic neuropathy: effects on microangiopathy. Diabet Med 7: 63-68. [Crossref]

5. Lewis EJ, Hunsicker LG, Bain RP, Rohde RD (1993) The effect of angiotensinconverting-enzyme inhibition on diabetic nephropathy. N Engl J Med 329: 1456-1462. [Crossref]
6. Veeresham C, Rama Rao A, Asres K (2014) Aldose reductase inhibitors of plant origin. Phytother Res 28: 317-333. [Crossref]

7. Valdes LJ. III, Mislankar SG, Paul AG (1987) Coleus barbatus (C. forskohlii) (Lamiaceae) and the potential new drug forskolin (Coleonol). Economic Botany 41: 474-483.

8. Pateraki I, Andersen-Ranberg J, Hamberger B, Heskes AM, Martens HJ, et al. (2014) Manoyl Oxide (13R), The biosynthetic precursor of forskolin, is synthesized in specialized root cork cells in coleus forskohlii. Plant physiology 164:1222-1236. [Crossref]

9. Forbes JM, Fukami K, Cooper ME (2007) Diabetic nephropathy: where hemodynamics meets metabolism. Exp Clin Endocrinol Diabetes 115: 69-84. [Crossref]

10. Huggett AS, Nixon DA (1957) Use of glucose oxidase, peroxidase and O-dianisidine in determination of blood and urinary glucose. Lancet 273: 368-370. [Crossref]

11. Hervey GR (1953) Determination of creatinine by Jaffe reaction. Nature 171: 1125.

12. Wybenga DR, Di, Giorgio J, Pileggi VJ (1971) Manual and automated methods for urea nitrogen measurement in whole serum. Clin Chem 17: 891-895. [Crossref]

13. Bradford MM (1976) A rapid and sensitive method for the quantization of microgram quantities of protein utilizing the principle of protein-dye binding. Anal Biochem 72 : 248-254. [Crossref]

14. Baig MA, Gawali VB, Patil RR, Naik SR (2012) Protective effect of herbomineral formulation (Dolabi) on early diabetic nephropathy in streptozotocin-induced diabetic rats. J Nat Med 66: 500-509. [Crossref]

15. Sensi M, Pricci F, Pugliese G, De Rossi MG, Petrucci AF, et al. (1996) Role of advanced glycation end-products (AGE) in late diabetic complications. Diabetes Res Clin Pract 28: 9-17. [Crossref]

16. Qi S, Wu D (2013) Bone marrow-derived mesenchymal stem cells protect against cisplatin-induced acute kidney injury in rats by inhibiting cell apoptosis. Int $\mathrm{J} \mathrm{Mol} \mathrm{Med}$ 32: 1262-1272. [Crossref]

17. Kim HY, Oh JH (1999) Screening of Korean forest plants for rat lens aldose reductase inhibition. Biosci Biotech Biochem 63:184-188. [Crossref]

18. Ohkawa H, Ohishi N, Yagi K (1979) Assay for lipid peroxides in animal tissues by thiobarbituric acid reaction. Analytical Biochemistry 95: 351-358. [Crossref]

19. Miranda K, Espy MG, Wink DA (2001) A rapid and simple spectrophotometric method for simultaneous detection of nitrate and nitrite. Nitric Oxide 5: 62-71. [Crossref]

20. Packham DK, Alves TP, Dwyer JP, Atkins R, de Zeeu w D, et al. (2012) Relative incidence of ESRD versus cardiovascular mortality in proteinuric type 2 diabetes and nephropathy: results from the DIAMETRIC (Diabetes Mellitus Treatment for Renal Insufficiency Consortium) database. Am J Kidney Dis 59: 75-83. [Crossref]

21. Rudberg S, Persson B, Dahlquist G (1992) Increased glomerular filtration rate as a predictor of diabetic nephropathy--an 8-year prospective study. Kidney Int 41: 822828. [Crossref]

22. Jiang WL, Zhang SP, Hou J, Zhu HB (2012) Effect of loganin on experimental diabetic nephropathy. Phytomedicine 19: 217-222. [Crossref]

23. Maack T, Johnson V, Kau ST, Figueiredo J, Sigulem D (1979) Renal filtration, transport, and metabolism of low-molecular-weight proteins: a review. Kidney Int 16: 251-270. [Crossref]

24. Brownlee M (2001) Biochemistry and molecular cell biology of diabetic complications. Nature 414: 813-820. [Crossref]

25. Oates PJ, Mylari BL (1999) Aldose reductase inhibitors: therapeutic implications for diabetic complications. Expert Opin Investig Drugs 8: 2095-2119. [Crossref]

26. Forbes JM, Cooper ME, Oldfield MD, Thomas MC (2003) Role of advanced glycation end products in diabetic nephropathy. J Am Soc Nephrol 14: S254-S258. [Crossref]

27. Lv L, Shao X, Wang L, Huang D, Ho CT, et al. (2010) Stilbene glucoside from Polygonum multiflorum Thunb.: a novel natural inhibitor of advanced glycation end product formation by trapping of methylglyoxal. J Agric Food Chem 58: 2239-2245. [Crossref]

28. Baynes JW, Thorpe SR (1999) Role of oxidative stress in diabetic complications: a new perspective on an old paradigm. Diabetes 48: 1-9. [Crossref]

29. Pitocco D, Zaccardi F, Di Stasio E, Romitelli F, Santini SA, et al. (2010) Oxidative stress, nitric oxide, and diabetes. Rev Diabet Stud 7: 15-25. [Crossref]

Copyright: (C2019 Damera S. This is an open-access article distributed under the terms of the Creative Commons Attribution License, which permits unrestricted use, distribution, and reproduction in any medium, provided the original author and source are credited. 